\title{
Phylogenetic distribution of protease inhibitors of the Kazal-family within the Arthropoda
}

\author{
Vincent van Hoef*, Bert Breugelmans, Jornt Spit, Gert Simonet, Sven Zels, Jozef Vanden Broeck
}

Department of Animal Physiology and Neurobiology, Zoological Institute K.U.Leuven, Naamsestraat 59, PO Box 02465, B-3000 Leuven, Belgium

\section{A R T I C L E I N F O}

\section{Article history:}

Received 29 May 2012

Received in revised form 30 October 2012

Accepted 30 October 2012

Available online 15 November 2012

\section{Keywords:}

PSTI

Kazal

Protease inhibitor

Arthropod

Phylogeny

\begin{abstract}
A B S T R A C T
In mammalian pancreatic cells, the pancreatic secretory trypsin inhibitor (PSTI) belonging to the Kazalfamily prevents the premature activation of digestive enzymes and thus plays an important role in a protective mechanism against tissue destruction by autophagy. Although a similar protective mechanism exists in Arthropoda, the distribution of these inhibitors in this phylum remains obscure. A comprehensive in silico search of nucleotide databases, revealed the presence of members of the Kazal-family in the four major subphyla of the Arthropoda. Especially in the Hexapoda and the Crustacea these inhibitors are widespread, while in the Chelicerata and Myriapoda only a few Kazal-like protease inhibitors were found. A sequence alignment of inhibitors retrieved in the digestive system of insects revealed a conservation of the PSTI characteristics and strong resemblance to vertebrate PSTI. A phylogenetic analysis of these inhibitors showed that they generally cluster according to their order. The results of this data mining study provide new evidence for the existence of an ancient protective mechanism in metazoan digestive systems. Kazal-like inhibitors, which play an important protective role in the pancreas of vertebrates, also seem to be present in Arthropoda.
\end{abstract}

(C) 2012 Elsevier Inc. All rights reserved.

\section{Introduction}

A healthy mammalian pancreas delivers its stored inactive digestive enzyme precursors to the gut. Once secreted in the gut lumen, the digestive enzymes are activated in a cascade-like manner, starting with the cleavage of trypsinogen into the active trypsin by enterokinase. Subsequently, trypsin activates the other proproteases needed for the digestion of proteins in the food [10]. To prevent premature activation of digestive enzymes and the resulting damage to cells and tissues, mammals express a protease inhibitor in their pancreatic cells called 'pancreatic secretory trypsin inhibitor' (PSTI) [11,16]. This inhibitor is a member of the numerous and diverse Kazal-family of protease inhibitors and binds to prematurely activated trypsin, interrupting the activation cascade. Typically, a mammalian Kazal-type serine protease inhibitor domain is 40-60 amino acids long, has a molecular mass of approximately $6500 \mathrm{Da}$ and has a conserved domain architecture $[3,13]$. This Kazal domain or motif has a general amino

\footnotetext{
* Corresponding author. Tel.: +32 16324260; fax: +32 16323902.

E-mail addresses: Vincent.vanHoef@bio.kuleuven.be, vvanhoef@hotmail.com (V. van Hoef), Bert.Breugelmans@bio.kuleuven.be (B. Breugelmans), Jornt.Spit@bio.kuleuven.be (J. Spit), Gert.Simonet@bio.kuleuven.be (G. Simonet), Sven.Zels@bio.kuleuven.be (S.Zels), Jozef.VandenBroeck@bio.kuleuven.be (J. Vanden Broeck).
}

acid sequence of $\mathrm{Cys}_{\mathrm{I}}-\mathrm{X}_{\mathrm{a}}-\mathrm{Cys}_{\mathrm{II}}-\mathrm{X}_{\mathrm{b}}-\mathrm{PVCys} \mathrm{III}_{\mathrm{II}} \mathrm{G}-\mathrm{X}_{\mathrm{C}}-\mathrm{TY}-\mathrm{X}_{\mathrm{d}}-\mathrm{Cys}_{\mathrm{IV}}-\mathrm{X}_{\mathrm{e}}-$ $\mathrm{Cys}_{\mathrm{V}}-\mathrm{X}_{\mathrm{f}}-\mathrm{G}-\mathrm{X}_{\mathrm{g}}-\mathrm{Cys}_{\mathrm{VI}}$ where the subscripts $\mathrm{a}, \mathrm{b}, \mathrm{c}, \mathrm{d}, \mathrm{e}, \mathrm{f}$ and $\mathrm{g}$ are integral numbers of amino acid residues. The six cysteine residues form three intra-domain disulfide bridges in a characteristic pattern $\left(\mathrm{Cys}_{\mathrm{I}}-\mathrm{Cys}_{\mathrm{V}}, \mathrm{Cys}_{\mathrm{II}}-\mathrm{Cys}_{\mathrm{IV}}\right.$ and $\left.\mathrm{Cys}_{\mathrm{III}}-\mathrm{Cys} \mathrm{VII}_{\mathrm{V}}\right)$ contributing to a tight three-dimensional conformation. The second amino acid C-terminal to the second cysteine is the important specificity determining P1-residue (see Fig. 2) [31].

The 'authentic' PSTI occurs only in vertebrate species $[1,8,11,23,24,41]$, which is logical since they are the only animal group with an actual pancreas. However, a study in 2006 revealed the presence of the PSTI-homolog Kazal1 in the endodermal cell layer of the body column of the freshwater polyp, Hydra magnipapillata [6]. The cells expressing Kazal1 showed the specific morphology of gland cells, with a multi-vacuolated cytoplasm corresponding to large secretory vesicles. Considering the similar structure and cellular localization, the authors speculated that Kazal1's function was to prevent the premature activation of digestive enzymes. An RNAi-mediated knockdown of this inhibitor resulted in severe autophagy of gland cells and epithelial digestive cells. This phenotype resembles pancreatitis - a disease which is associated with dysfunctional PSTI in vertebrates. So, even though Hydra does not possess a pancreas, a similar protease inhibitor seems to have the same protective role as PSTI has in vertebrates. Cnidaria - the phylum Hydra belongs to - are an evolutionary sister group to the Bilateria (including vertebrates and arthropods), 
suggesting an ancient origin for this protective mechanism in a common ancestor. Since Arthropoda emerged only after the divergence of Cnidaria and Bilateria more than 580 Mya [5], a comparable defensive role for PSTI-like proteins in arthropods seems plausible. Further evidence for a similar function in arthropods was observed in the locust Locusta migratoria [36]. Again, an RNAi-mediated knockdown of a locust-specific PSTI-like protein (LmPSTI) resulted in a phenotype not unlike that observed in mammals suffering from pancreatitis (i.e. the occurrence of autophagy in the insect's caeca).

This manuscript reports on a detailed, comparative in silico data mining study of PSTI-like protein precursors among Arthropoda with a special emphasis on the distribution in Insecta. To our knowledge, no arthropod PSTI-homologs have been characterized as such so far (except for LmPSTI in L. migratoria). However, there have been numerous reports of Kazal-type family protease inhibitors (PSTI being an important member of the Kazal-type family inhibitors) with a variety of suggested functions in various arthropod classes and orders including species, such as Bombyx mori [42], Rhodnius prolixus [9], Aedes aegyptii [39] and several crustaceans [4,7,19,38].

\section{Materials and methods}

\subsection{Database searches}

Arthropod homologs of PSTI were searched for in silico in EST (Expressed Sequence Tags) databases using a list of 15 known vertebrate PSTI precursor sequences from the Uniprot protein database (http://www.uniprot.org) as a query (see additional data). To check and further complement previous search results, novel arthropod sequences were used as additional queries. Detailed searches were performed on a vast number of nucleotide sequences available via the BLAST (Basic Local Alignment Search Tool) function accessible on the NCBI platform (http://www.ncbi.nlm.nih.gov/BLAST/). Complementary to this, various databases of individual species containing new sequences that are not yet incorporated into the NCBI platform were analyzed (BeetleBase; beetlebase.org, FlyBase; flybase.org).

\subsection{Strategy}

The data mining search was performed in a systematic way, covering as many classes and orders as possible. Per arthropod subphylum, EST sequence data sets were analyzed for the presence of PSTI homologs and, whenever this was possible, additional searches were performed in the classes, orders and families of the subphylum. Since Kazal-like inhibitors (the peptide family PSTI belongs to) are a very numerous family with many and diverse functions, a distinction was made between EST sequences originating from the organisms' digestive system and others. This distinction was made to focus on the novel inhibitors that potentially have a similar role as the mammalian PSTI - namely to protect the organism from damage due to prematurely activated digestive enzymes.

\subsection{Sequence comparison and phylogenetic analysis of insect PSTI-like proteins}

The PSTI-like precursors obtained from insect EST sequences originating from the digestive system were restricted in length to the two exterior Cys residues $\left(\mathrm{Cys}_{\mathrm{I}}\right.$ to $\left.\mathrm{Cys} \mathrm{S}_{\mathrm{VI}}\right)$ and aligned using ClustalW (http://www.ebi.ac.uk/Tools/msa/clustalw2/) and visualized in the perl/tk-based tool Aline (http://crystal.bcs.uwa. edu.au/px/charlie/software/aline/). The alignment file which resulted from the ClustalW alignment was used as an input file to visualize the phylogeny of the PSTI-like precursors in the free software program PHYLIP (PHYLogeny Inference Package) (http://evolution.genetics.washington.edu/phylip.html) using the maximum parsimony method.

\section{Results}

By almost any measure, arthropods are the most diverse and successful group of animals on the planet. They make up over three quarters of all known currently living and fossil organisms, and are represented by - according to scientists' recent estimates - 3.7 million species [14]. So far, however, 'only' around 855,000 species have been described, which leaves approximately $75 \%$ of the contemporary arthropod species awaiting scientific description. This large number of species is divided into four subphyla: Myriapoda (centipedes, millipedes, etc.), Chelicerata (horseshoe crabs, spiders and pycnogonids), Crustacea (shrimps, crabs, etc.) and Hexapoda (insects and springtails). As described in Section 2, a similarity search was performed to discover novel Kazal-like inhibitors and potential PSTI homologs. The results are visualized in Fig. 1.

\subsection{PST-like inhibitors in Myriapoda}

Myriapoda is a subphylum of the Arthropoda containing among others the centipedes and the millipedes (hence the name Myriapoda, which means 10,000 legs in Greek). They are subdivided in four subphyla: the Chilopoda, the Diplopoda, the Pauropoda and the Symphyla. Genetic data of this animal group are scarce, with only 4461 EST sequences and 3893 nucleotide sequences submitted to the NCBI platform (and almost completely confined to the diplopodans). A similarity search through EST data, revealed one significant hit in the African giant black millipede, Archispirostreptus gigas. Since the A. gigas EST sequences originated from a whole animal, a further tissue distribution was not available. Although several Kazal-like inhibitor features are present (6 cysteines, conserved amino acids) and the P1-residue is a Lys (suggesting trypsin inhibitory specificity), other characteristics differ from a typical Kazal-domain (most notably, a remarkably short amino acid stretch between $\mathrm{Cys}_{\mathrm{V}}$ and $\mathrm{Cys}_{\mathrm{VI}}$ ). In the Chilopoda, Pauropoda and Symphyla, no PSTI-homolog could be discovered.

\subsection{PSTI-like inhibitors in Chelicerata}

The subphylum of Chelicerata is currently subdivided in three classes: the Arachnida (arachnids), the Pycnogonida (sea spiders) and the Merostomata (horseshoe crabs). Genetic data about this subphylum are more abundant in comparison with data about Myriapoda - especially the Arachnida are well-represented. Searching this relative abundance of nucleotide information did, however, not result in a large number of Kazal-like inhibitors. In the Southeast Asian horseshoe crab, Carcinoscorpius rotundicauda (a member of the Merostomata), and the Black-legged tick, Ixodes scapularis (a member of the Arachnida), respectively two and one putative Kazal-like inhibitors were found. Not surprisingly, these two species are greatly overrepresented in the nucleotide information available about their class (46.5\% and $93.5 \%$ for Ixodes and Carcinoscorpius, respectively). A further localization in the digestive system could not be deduced for these inhibitors. A search through the very recently sequenced genome of the spider mite, Tetranychus urticae revealed the presence of two putative Kazal-type inhibitors [12]. Searching through currently available pycnogonid nucleotide information did not yield potential Kazaltype inhibitors.

\subsection{PSTI-like inhibitors in Crustacea}

Crustacea is a large and diverse subphylum of the Arthropoda, including many commercially (and gastronomically) important 


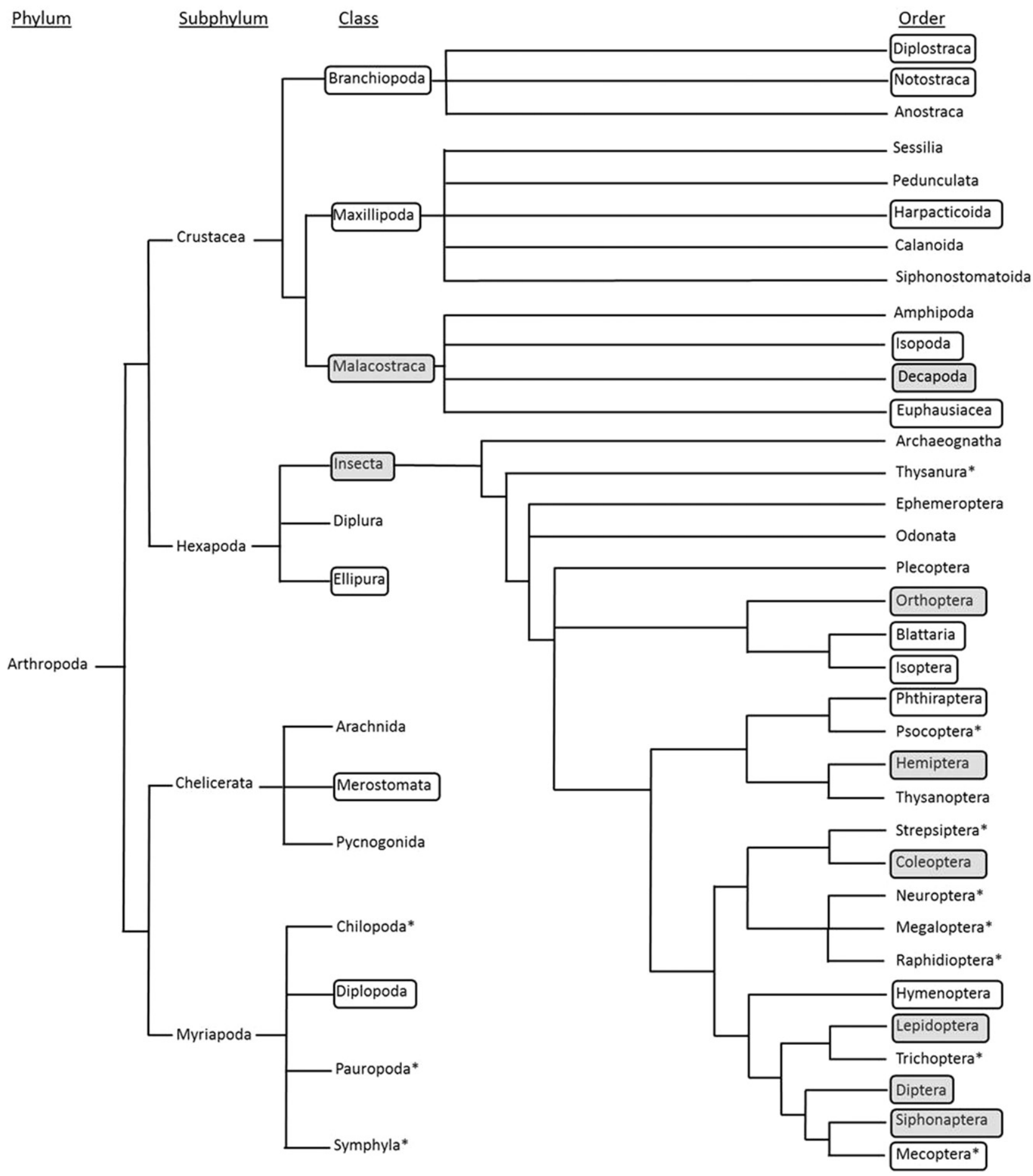

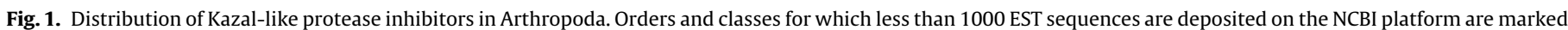

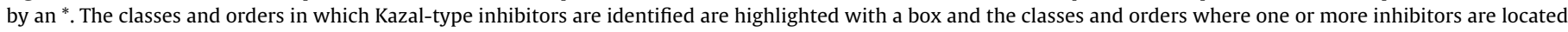
in the digestive system are marked in gray.

species, such as the common freshwater shrimp (Gammarus pulex), the Pacific white shrimp (Litopenaeus vannamei) and the American lobster (Homarus americanus). A lot of sequence data are available for these species and several genome projects are generating a growing amount of information. Three classes of the subphylum Crustacea were examined for the presence of Kazal-like protease inhibitors and possible PSTI homologs: the class of Branchiopoda (comprises fairy shrimp, clam shrimp and Cladocera), the class of Maxillopoda (includes barnacles and copepods) and the class of
Malacostraca (displays a greater diversity in body forms than any other animal class and includes species such as crab, lobster, krill and shrimp).

In the NCBI platform, Branchiopoda are mainly represented by Daphnia species of the order of Diplostraca (around 172,000 ESTs). An earlier search in the draft assembly of the genome of Daphnia pulex had already shown the presence of at least 35 Kazal-type inhibitor domains [4]. Our similarity search in the EST sequences indeed revealed several putative Kazal-like inhibitors. 
Their (possible) localization in the digestive tract could however not be deduced from the nucleotide data. The order of Notostraca (shield shrimps and tadpole shrimps) also appears to contain at least one Kazal-like inhibitor in Triops cancriformis, despite the relative scarcity of EST information. Anostraca (fairy shrimps) do not appear to contain Kazal-like inhibitors, despite being relatively well represented in the EST databases.

The class of Maxillopoda contains many orders (in Fig. 1 only the orders for which EST data was available are represented), but only in the Harpacticoida and Siphonostomatoida putative Kazallike inhibitors were present.

The large and diverse class of Malacostraca possesses Kazallike inhibitors in three orders: Isopoda (pill bugs, wood lice and sea slaters), Euphausiacea (krill) and Decapoda. In the Isopoda one homolog could be found in Euridice pulchra. Interestingly, this inhibitor seems to lack $\mathrm{Cys}_{\mathrm{II}}$ and $\mathrm{Cys}_{\mathrm{IV}}$ (resulting in two disulfide bridges instead of the normal three). This kind of 'atypical Kazal domains' has been described before in several invertebrate species, such as Galleria mellonella [27], Argopecten irradians [43] and Chlamys farreri [37]. In the EST information of the Euphausiacea, a double domain Kazal-like inhibitor was retrieved in the head (but not the digestive tract) of Euphasia superba. Earlier studies had already revealed the presence of many Kazal-like inhibitors in the order of the Decapoda. For example in Penaeus monodon [33], L. vannamei [18], Pacifastacus leniusculus [19] and Procambarus clarkia [40] multiple domain Kazal-like inhibitors have been identified. They are important in several biological processes, such as reproduction, protection against pathogen-derived proteinases and antimicrobial activity. A multi-domain Kazal-like inhibitor from L. vannamei was also found in the organism's hepatopancreas. This organ appears in the digestive tract of certain arthropods, mollusks and fish and is responsible for the functions which are provided separately by the liver and the pancreas in mammals. Several studies have shown that this organ stores and secretes digestive enzymes, such as serine proteases [20,21,34]. In this case, Kazal-type protease inhibitors native to the hepatopancreas might play a role in preventing cellular damage after premature enzyme activation.

\subsection{PSTI-like inhibitors in Hexapoda}

The subphylum of Hexapoda is the largest (in terms of number of species) grouping of arthropods and includes the classes of Ellipura (springtails), Diplura (two-pronged bristletails) and Insecta. Their name was derived from an important common feature: a consolidated thorax with three pairs of legs (in contrast to other arthropods, most of which have more than three pairs of legs). Insects in particular are highly rich in species and represent more than half of all known living organisms. This diversity and their economic importance - both beneficial and destructive - are reflected in the amount of nucleotide data available: $76 \%$ of the arthropod EST sequences on the NCBI platform originate from the class of Insecta.

In Ellipura, Kazal-type inhibitors were found in two species of the order of Collembola: Folsomia candida and Onychiurus arcticus (Arctic springtail). No information on their tissue distribution is available.

In Diplura, no Kazal-type inhibitors were retrieved, possibly due to the current shortage of available sequence data for this class.

In insects, several previous studies have shown the presence of Kazal-like inhibitors in species, such as B. mori [42], Drosophila melanogaster [26], A. aegyptii [30], Triatoma infestans [22] and $R$. prolixus [9]. The biological and physiological functions they perform are diverse. For example, blood-sucking insects, such as $R$. prolixus and T. infestans, produce Kazal-type proteinase inhibitors (rhodniin and infestin, respectively) which display a strong affinity for thrombin and play an important role as anticoagulant during the ingestion of a blood meal. On the other hand, in moths, such as B. mori, a Kazal-type inhibitor is produced in the silk glands and is present in the cocoon silk besides the major silk proteins. The presence of this serine protease inhibitor and its activity against the bacterial subtilisin and fungal proteinase $\mathrm{K}$ suggests a function in the protection of silk cocoon against degradation by microbial proteinases [42]. For other inhibitors the function remains to be elucidated.

Our search in insect EST-databases revealed additional potential Kazal-type inhibitors in the majority of insect orders. These inhibitors seem to be present throughout the class of Insecta: from hemimetabolous orthopteran, blattarian and isopteran species to holometabolous hymenopteran, lepidopteran, dipteran, mecopteran and siphonapteran species. In the order of Orthoptera, Kazal-type inhibitors are found in the two major suborders: Caelifera (locusts and grasshoppers) and Ensifera (crickets and katydids). In Hemiptera, Kazal-like inhibitors are found in all three important clades, i.e. the clade of the true bugs (Heteroptera), the cicadas (Auchenorrhyncha) and the aphids (Sternorrhyncha). The presence of these inhibitors in phloem-feeding aphids raises some interesting questions concerning their function, since these organisms are believed to have only marginal proteolytic digestion by proteases (and mainly by cysteine proteinases). A recent study however, showed that there appears to be significant proteolytic digestion in cereal aphids, allowing for a regulatory role of these inhibitors in the activation of digestive proteases - even in aphids [29]. In six other orders EST-data showed that Kazal-type inhibitors are present in the digestive tract and could therefore have a similar protective role as PSTI-like inhibitors in vertebrates and Hydra. These orders were the Orthoptera (grasshoppers and locusts), Hemiptera (bugs), Coleoptera (beetles), Lepidoptera (butterflies and moths), Diptera (flies) and Siphonaptera (fleas). Additional searches in FlyAtlas (flyatlas.org) revealed that Kazal-like inhibitors are mainly present in the midgut of larval Drosophila. This confirms the results of a study by Niimi et al., which locates similar inhibitors in the secretory pathway and the cytosol of the Drosophila midgut [26]. A sequence comparison and phylogenetic analysis at the species level of these six orders is presented in the next paragraph.

\subsection{Sequence comparison and phylogenetic analysis of insect PSTI-like proteins}

By searching the available insect EST-data, 49 new Kazal-like inhibitors were predicted which are expressed in the digestive system and thus are potential PSTI-like peptides. Aligning these with human PSTI revealed several conserved amino acids (see Fig. 2). In all peptides, six cysteine residues are conserved which form a disulfide linkage pattern typical for Kazal-like inhibitors. The specificity determining P1-residue is predominantly Arg or Lys, which is indicative of trypsin inhibitors and in accordance with their suggested function: preventing trypsin from activating the (other) proenzymes prematurely. In some cases, however, another residue is found at this site; an often encountered P1-variant is Leu, which suggests an inhibitory preference for chymotrypsin, just like Met, Phe and Tyr. Two species (R. prolixus 2 and 0 . nubilalis 3) have an Asp at this position, suggesting an inhibitory activity toward cysteine proteases, which is uncommon for the serine protease targeting Kazal-like inhibitors. Inhibition of cysteine proteases excreted by the bacterium Porphyromonas gingivalis by PSTI has been demonstrated [2], but these cysteine proteases - called gingipains - are Lys- and Arg-specific allowing for PSTI to be a suitable substrate and effective inhibitor. For $R$. prolixus 2, however, another role has been suggested. This inhibitor is part of a multi-domain Kazal-type inhibitor (rhodniin) directed toward thrombin; domain 1 interacts with thrombin via the classical method described for Kazallike inhibitors while domain 2 facilitates the thrombin-rhodniin 

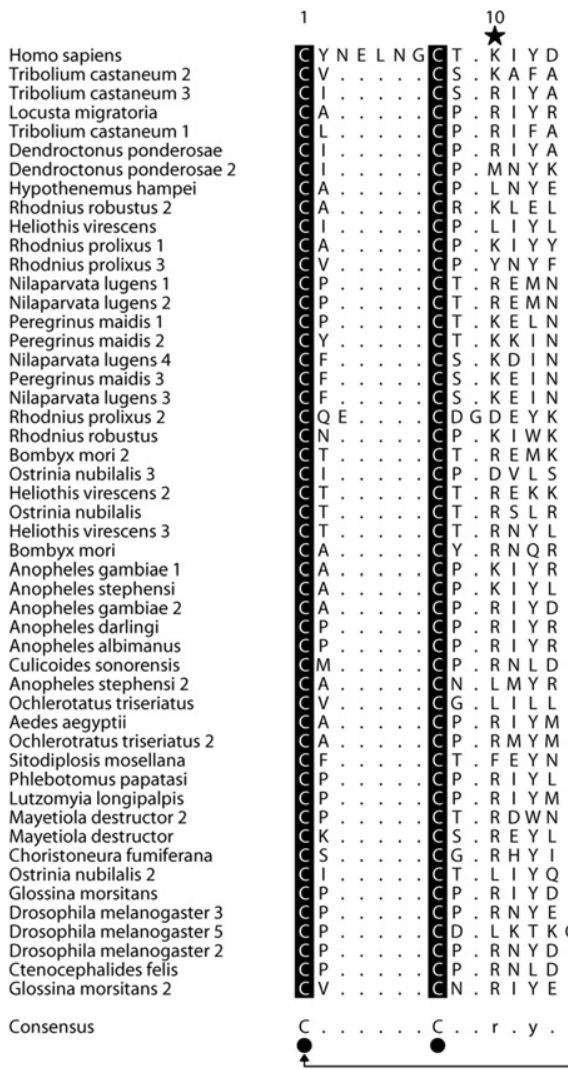

20

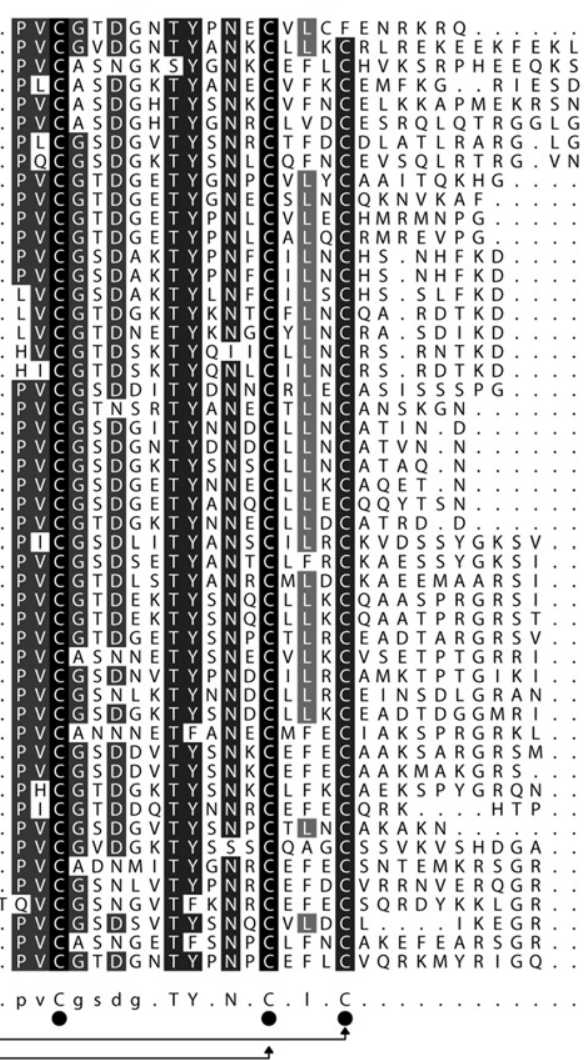

40

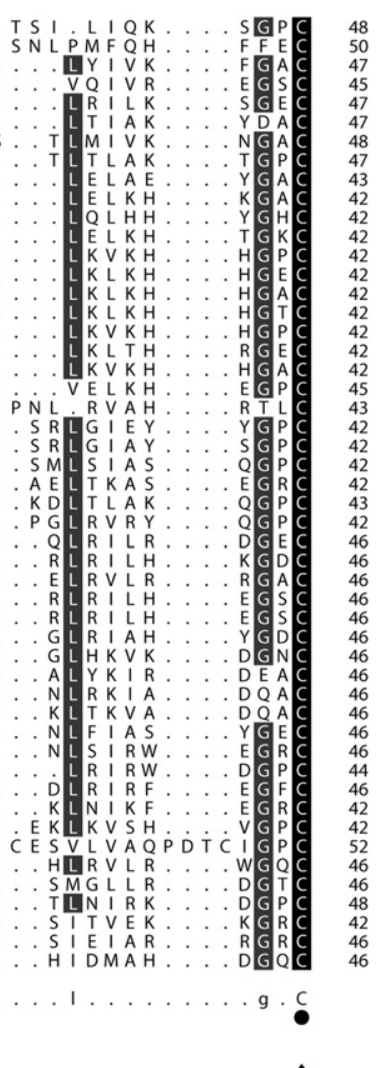

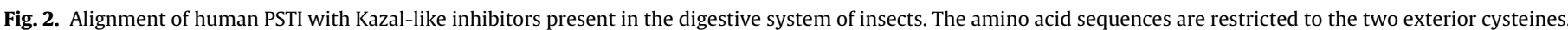

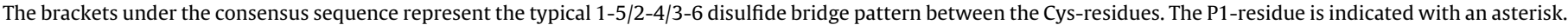

interaction through electrostatic interactions independent of its P1-residue [35]. The role of these non-trypsin inhibitors in stopping the zymogen activation cascade is thus not entirely clear, but one could imagine functions, for instance in preventing damage from already activated chymotrypsin or possibly even cysteine proteases. Although a considerable sequence variation can be observed between the PSTI-homologs, the region between the Pro two positions before $\mathrm{Cys}_{\mathrm{III}}$ and $\mathrm{Cys}_{\mathrm{V}}$ has a higher degree of conservation than the rest of the peptide. Also, a Leu and a Gly residue, situated between $\mathrm{Cys}_{\mathrm{V}}$ and $\mathrm{Cys}_{\mathrm{VI}}$, are fairly well conserved.

\section{Discussion}

A similarity search for Kazal-type inhibitors in EST sequences originating from arthropod species revealed that this inhibitor family is present in the four major subphyla. In particular in the Hexapoda and Crustacea, Kazal-like inhibitors seem widespread with members of this family found in all studied crustacean classes and in two out of the three studied hexapodan classes. The absence of these inhibitors in some classes and orders seems merely a consequence of the current scarcity of EST data, rather than a reflection of their true distribution.

The subject of this study is a particular member of the Kazal family, namely PSTI. The detection of PSTI in the EST data is complicated because of their sequence resemblance to other Kazal-type inhibitors and the absence of functionally characterized arthropod PSTI-like inhibitors. Therefore, only inhibitors expressed in the digestive system were upheld for a sequence alignment and phylogenetic analysis of putative PSTI-like peptides from insects. In general, insect Kazal-like protease inhibitors resemble their mammalian counterparts fairly well, except for the number of amino acids between the first two conserved cysteine residues. In mammals, usually six amino acids occupy the space between $\mathrm{Cys}_{\mathrm{I}}$ and $\mathrm{Cys}_{\mathrm{II}}$, while in invertebrates this is typically limited to just one or two residues. According to Hemmi et al., this results in a less flexible conformation causing the invertebrate inhibitors to be more (protease) specific [15].

A recent study demonstrated the high sequence variability of Kazal-like inhibitors in Crustacea, obscuring the evolutionary connections [4]. In contrast, Kazal-like inhibitors of the digestive tract in insects appear not to be equally variable. The newly found PI's originated from species of six insect orders - including the largest order: the Coleoptera - and a cladogram shows that they generally cluster together according to their order (see Fig. 3). However, the tree shown in Fig. 3 does not completely reflect relatedness between species or orders. For example, in our analysis lepidopteran PSTI-homologs seem more similar to hemipteran PSTIs, while actually Lepidoptera are nearer to Diptera. Also the fact that LMPSTI is placed among the PSTI-homologs of beetles does not seem to mimic the orthopteran and coleopteran phylogeny.

In many species, multiple isoforms are found. Whether these are the product of gene multiplication, multi-domain inhibitors or the result of alternative splicing remains to be investigated. The functional PSTI-homolog Kazal1 in the freshwater polyp H. magnipapillata is a three-domain inhibitor but in vertebrates, PSTI is mostly a single domain inhibitor. In the rat, however, an additional PSTI-like inhibitor is found with a possible function as a monitor peptide which observes food levels in the gut and subsequently regulates CCK secretion [25]. PSTI also has some structural similarities to epidermal growth factor (EGF). They share $\pm 50 \%$ amino acid sequence homology and have a similar number of residues and three disulfide bridges [17,32]. In addition, PSTI was shown to 


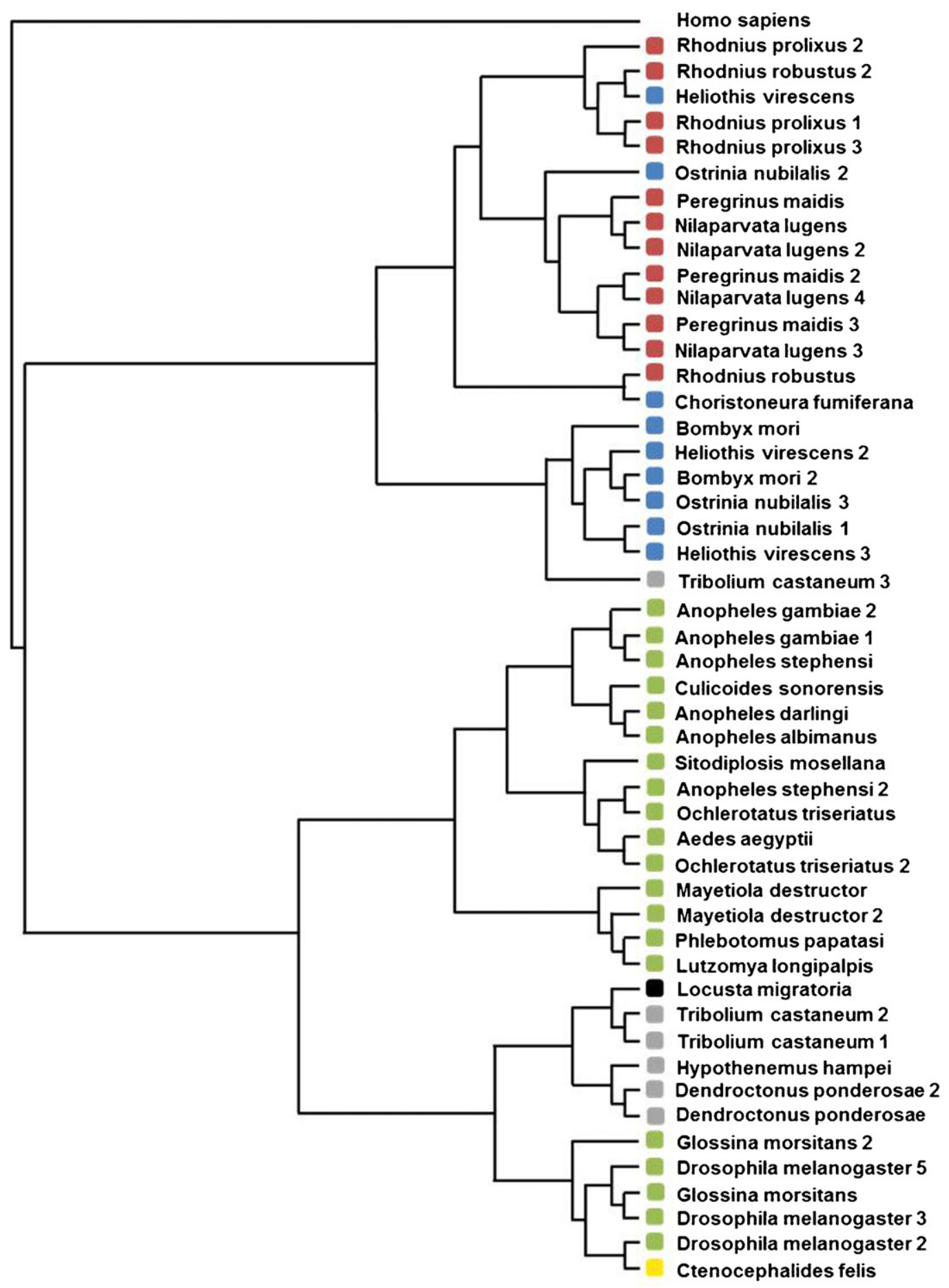

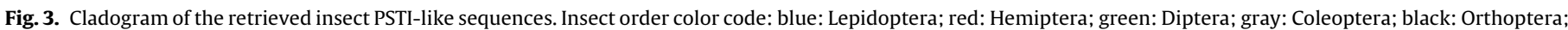
yellow: Siphonaptera. (For interpretation of the references to color in this figure legend, the reader is referred to the web version of the article.)

stimulate the growth of several cell lines and is able to bind the EGF receptor [28]. Therefore, other and divergent functions for some of the isoforms of Kazal-type PSTI-like inhibitors in invertebrates cannot be excluded.

\section{Acknowledgments}

The authors gratefully acknowledge the K.U. Leuven Research Foundation (GOA/11/02), the Research Foundation of Flanders (FWO-Flanders) and the Interuniversity Attraction Poles programme (Belgian Science Policy Grant P6/14) for financial support. J.S. and S.Z. were supported by the IWT (Instituut voor de aanmoediging van innovatie door Wetenschap en Technologie in Vlaanderen) and B.B. obtained a postdoctoral research fellowship from the FWO.

\section{References}

[1] Agerberth B, Ostenson CG, Efendic S, Jornvall H. Pancreatic secretory trypsin inhibitor (PSTI) isolated from pig intestine. Influence on insulin and somatostatin release. FEBS Lett 1991;281:227-30. 
[2] Bania J, Kubiak A, Wojtachnio K, Polanowski A. Pancreatic secretory trypsin inhibitor acts as an effective inhibitor of cysteine proteinases gingipains from Porphyromonas gingivalis. J Periodontal Res 2008;43:232-6.

[3] Bartelt DC, Shapanka R, Greene LJ. The primary structure of the human pancreatic secretory trypsin inhibitor. Amino acid sequence of the reduced S-aminoethylated protein. Arch Biochem Biophys 1977;179:189-99.

[4] Cerenius L, Liu H, Zhang Y, Rimphanitchayakit V, Tassanakajon A, Gunnar Andersson $M$, et al. High sequence variability among hemocyte-specific Kazal-type proteinase inhibitors in decapod crustaceans. Dev Comp Immunol 2010;34:69-75.

[5] Chen JY, Oliveri P, Gao F, Dornbos SQ, Li CW, Bottjer DJ, et al. Precambrian animal life: probable developmental and adult cnidarian forms from Southwest China. Dev Biol 2002;248:182-96.

[6] Chera S, de Rosa R, Miljkovic-Licina M, Dobretz K, Ghila L, Kaloulis K, et al. Silencing of the hydra serine protease inhibitor Kazal1 gene mimics the human SPINK1 pancreatic phenotype. J Cell Sci 2006;119:846-57.

[7] Donpudsa S, Soderhall I, Rimphanitchayakit V, Cerenius L, Tassanakajon A, Soderhall K. Proteinase inhibitory activities of two two-domain Kazal proteinase inhibitors from the freshwater crayfish Pacifastacus leniusculus and the importance of the $\mathrm{P}(2)$ position in proteinase inhibitory activity. Fish Shellfish Immunol 2010;29:716-23.

[8] Freeman TC, Playford RJ, Quinn C, Beardshall K, Poulter L, Young J, et al. Pancreatic secretory trypsin inhibitor in gastrointestinal mucosa and gastric juice. Gut 1990;31:1318-23.

[9] Friedrich T, Kroger B, Bialojan S, Lemaire HG, Hoffken HW, Reuschenbach P, et al. A Kazal-type inhibitor with thrombin specificity from Rhodnius prolixus. J Biol Chem 1993;268:16216-22.

[10] Gorelick FS, Otani T. Mechanisms of intracellular zymogen activation. Baillieres Best Pract Res Clin Gastroenterol 1999;13:227-40.

[11] Graf R, Klauser S, Fukuoka SI, Schiesser M, Bimmler D. The bifunctional rat pancreatic secretory trypsin inhibitor/monitor peptide provides protection against premature activation of pancreatic juice. Pancreatology 2003;3:195-206.

[12] Grbic M, Van Leeuwen T, Clark RM, Rombauts S, Rouze P, Grbic V, et al. The genome of Tetranychus urticae reveals herbivorous pest adaptations. Nature 2011;479:487-92.

[13] Greene LJ, Pubols MH, Bartelt DC. Human pancreatic secretory trypsin inhibitor. Methods Enzymol 1976;45:813-25.

[14] Hamilton AJ, Basset Y, Benke KK, Grimbacher PS, Miller SE, Novotny V, et al. Quantifying uncertainty in estimation of tropical arthropod species richness. Am Nat 2010;176:90-5.

[15] Hemmi H, Kumazaki T, Yamazaki T, Kojima S, Yoshida T, Kyogoku Y, et al Inhibitory specificity change of the ovomucoid third domain of the silve pheasant upon introduction of an engineered Cys14-Cys39 bond. Biochemistry 2003;42:2524-34.

[16] Hirota M, Ohmuraya M, Baba H. The role of trypsin, trypsin inhibitor, and trypsin receptor in the onset and aggravation of pancreatitis. J Gastroenterol 2006;41:832-6.

[17] Hunt LT, Barker WC, Dayhoff MO. Epidermal growth factor: internal duplication and probable relationship to pancreatic secretory trypsin inhibitor. Biochem Biophys Res Commun 1974;60:1020-8.

[18] Jimenez-Vega F, Vargas-Albores F. A four-Kazal domain protein in Litopenaeus vannamei hemocytes. Dev Comp Immunol 2005;29:385-91.

19] Johansson MW, Keyser P, Soderhall K. Purification and cDNA cloning of a fourdomain Kazal proteinase inhibitor from crayfish blood cells. Eur J Biochem 1994;223:389-94

20] Lehnert SA, Johnson SE. Expression of hemocyanin and digestive enzyme messenger RNAs in the hepatopancreas of the Black Tiger Shrimp Penaeus monodon. Comp Biochem Physiol B: Biochem Mol Biol 2002;133:163-71.

[21] Li XC, Zhang RR, Sun RR, Lan JF, Zhao XF, Wang JX. Three Kazal-type serine proteinase inhibitors from the red swamp crayfish Procambarus clarkii an the characterization, function analysis of hcPcSPI2. Fish Shellfish Immunol 2010;28:942-51.

22] Lovato DV, Nicolau de Campos IT, Amino R, Tanaka AS. The full-length cDNA of anticoagulant protein infestin revealed a novel releasable Kazal domain, a neutrophil elastase inhibitor lacking anticoagulant activity. Biochimie 2006;88:673-81.

23] Marks WH, Ohlsson K. Isolation and partial characterization of the pancreatic secretory trypsin inhibitor in the rat. Biochim Biophys Acta 1982;717:91-7.
[24] Marks WH, Ohlsson K. A radioimmunoassay for rat pancreatic secretory trypsin inhibitor. Scand J Gastroenterol 1983;18:401-5

[25] Miyasaka K, Funakoshi A, Nakamura E, Teraoka H. Regulation of gene expression of pancreatic secretory trypsin inhibitor- 61 and -56 by bile and pancreatic juice in rats. Pancreas 1995;11:246-55

[26] Niimi T, Yokoyama H, Goto A, Beck K, Kitagawa Y. A Drosophila gene encoding multiple splice variants of Kazal-type serine protease inhibitor-like proteins with potential destinations of mitochondria, cytosol and the secretory pathway. Eur J Biochem 1999;266:282-92.

[27] Nirmala X, Kodrik D, Zurovec M, Sehnal F. Insect silk contains both a Kunitz-type and a unique Kazal-type proteinase inhibitor. Eur J Biochem 2001;268:2064-73

[28] Ozaki N, Ohmuraya M, Hirota M, Ida S, Wang J, Takamori H, et al. Serine protease inhibitor Kazal type 1 promotes proliferation of pancreatic cance cells through the epidermal growth factor receptor. Mol Cancer Res 2009;7: 1572-81.

[29] Pyati P, Bandani AR, Fitches E, Gatehouse JA. Protein digestion in cereal aphids (Sitobion avenae) as a target for plant defence by endogenous proteinase inhibitors. J Insect Physiol 2011;57:881-91.

[30] Ribeiro JM, Arca B, Lombardo F, Calvo E, Phan VM, Chandra PK, et al. An annotated catalogue of salivary gland transcripts in the adult female mosquito Aedes aegypti. BMC Genomics 2007;8:6.

[31] Rimphanitchayakit V, Tassanakajon A. Structure and function of invertebrate Kazal-type serine proteinase inhibitors. Dev Comp Immunol 2010;34 377-86.

[32] Scheving LA. Primary amino acid sequence similarity between human epidermal growth factor-urogastrone, human pancreatic secretory trypsin inhibitor, and members of porcine secretin family. Arch Biochem Biophys 1983;226:411-3.

[33] Somprasong N, Rimphanitchayakit V, Tassanakajon A. A five-domain Kazaltype serine proteinase inhibitor from black tiger shrimp Penaeus monodon and its inhibitory activities. Dev Comp Immunol 2006;30:998-1008.

[34] Sriket C, Benjakul S, Visessanguan W. Characterisation of proteolytic enzymes from muscle and hepatopancreas of fresh water prawn (Macrobrachium rosenbergii). J Sci Food Agric 2011;91:52-9.

[35] van de Locht A, Lamba D, Bauer M, Huber R, Friedrich T, Kroger B, et al Two heads are better than one: crystal structure of the insect derived double domain Kazal inhibitor rhodniin in complex with thrombin. EMBO J 1995; 14 : 5149-57.

[36] van Hoef V, Breugelmans B, Spit J, Simonet G, Zels S, Billen J, et al. Functional analysis of a pancreatic secretory trypsin inhibitor-like protein in insects: Silencing effects resemble the human pancreatic autodigestion phenotype. Insect Biochem Mol Biol 2011:41:688-95.

[37] Wang B, Zhao J, Song L, Zhang H, Wang L, Li C, et al. Molecular cloning and expression of a novel Kazal-type serine proteinase inhibitor gene from Zhikong scallop Chlamys farreri, and the inhibitory activity of its recombinant domain. Fish Shellfish Immunol 2008;24:629-37.

[38] Wang ZH, Zhao XF, Wang JX. Characterization, kinetics, and possible function of Kazal-type proteinase inhibitors of Chinese white shrimp, Fenneropenaeus chinensis. Fish Shellfish Immunol 2009:26:885-97.

[39] Watanabe RM, Soares TS, Morais-Zani K, Tanaka-Azevedo AM, Maciel C, Capurro ML, et al. A novel trypsin Kazal-type inhibitor from Aedes aegypti with thrombin coagulant inhibitory activity. Biochimie 2010;92:933-9.

[40] Zeng Y, Lu CP. Identification of differentially expressed genes in haemocytes of the crayfish (Procambarus clarkii) infected with white spot syndrome virus by suppression subtractive hybridization and cDNA microarrays. Fish Shellfish Immunol 2009;26:646-50.

[41] Zhao M, Naude RJ, Muramoto K, Oelofsen W. Purification and characterization of ostrich pancreatic secretory trypsin inhibitor. Int J Pept Protein Res 1996:48:174-81.

[42] Zheng QL, Chen J, Nie ZM, Lv ZB, Wang D, Zhang YZ. Expression, purification and characterization of a three-domain Kazal-type inhibitor from silkworm pupae (Bombyx mori). Comp Biochem Physiol B: Biochem Mol Biol 2007;146: 234-40.

[43] Zhu L, Song L, Chang Y, Xu W, Wu L. Molecular cloning, characterization and expression of a novel serine proteinase inhibitor gene in bay scallops (Argopecten irradians, Lamarck 1819). Fish Shellfish Immunol 2006;20 320-31. 